\title{
Single-Cell Reconstruction of Oxytocinergic Neurons Reveals Separate Hypophysiotropic and Encephalotropic Subtypes in Larval Zebrafish
}

\author{
DUlrich Herget, ${ }^{1}$ Jose Arturo Gutierrez-Triana, ${ }^{1}$ @Oriana Salazar Thula, ${ }^{1}$ Boris Knerr, ${ }^{1}$ and ${ }^{\circledR}$ Soojin \\ Ryu $^{1,2}$
}

DOI:http://dx.doi.org/10.1523/ENEURO.0278-16.2016

${ }^{1}$ Developmental Genetics of the Nervous System, Max Planck Institute for Medical Research, 69120 Heidelberg, Germany, ${ }^{2}$ Focus Program Translational Neuroscience, University Medical Center, Johannes Gutenberg University Mainz, Langenbeckstr. 1, 55131, Mainz, Germany

\section{Visual Abstract}

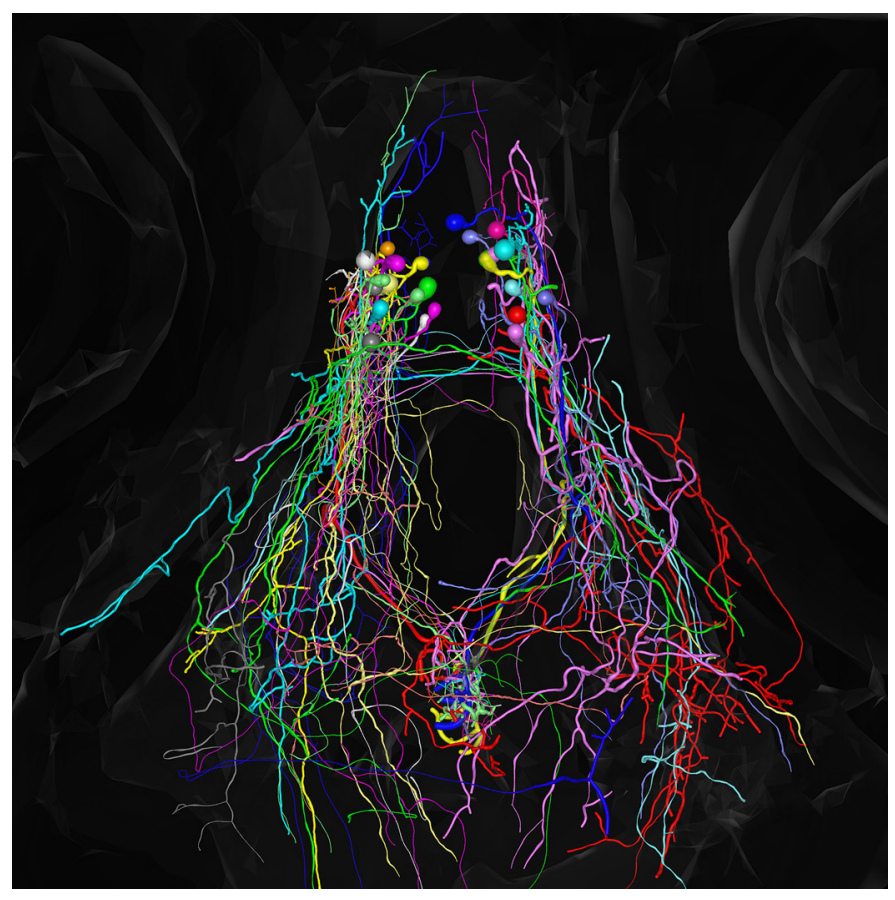

\section{Significance Statement}

We used the Brainbow technique to reconstruct the morphology and projection patterns of oxytocinergic neurons in larval zebrafish, revealing diverse and complex brainwide innervation patterns originating from a small cluster of cells within the neurosecretory preoptic area. Central target areas include the tectum, hypothalamus, and telencephalon. This is the first comprehensive whole-brain morphology characterization of oxytocinergic neurons, to our knowledge. $3 \mathrm{D}$ registration reveals spatially distinct subtypes of oxytocinergic neurons. One group with morphologically complex projections reaches into distinct brain regions, presumably for neuromodulation, whereas another group features simpler projections innervating the pituitary, presumably for endocrine release. These two groups are spatially segregated, suggesting an evolutionarily ancient anatomical separation of oxytocin cell subtypes. 
Oxytocin regulates a diverse set of processes including stress, analgesia, metabolism, and social behavior. How such diverse functions are mediated by a single hormonal system is not well understood. Different functions of oxytocin could be mediated by distinct cell groups, yet it is currently unknown whether different oxytocinergic cell types exist that specifically mediate peripheral neuroendocrine or various central neuromodulatory processes via dedicated pathways. Using the Brainbow technique to map the morphology and projections of individual oxytocinergic cells in the larval zebrafish brain, we report here the existence of two main types of oxytocinergic cells: those that innervate the pituitary and those that innervate diverse brain regions. Similar to the situation in the adult rat and the adult midshipman, but in contrast to the situation in the adult trout, these two cell types are mutually exclusive and can be distinguished based on morphological and anatomical criteria. Further, our results reveal that complex oxytocinergic innervation patterns are already established in the larval zebrafish brain.

Key words: Brainbow; morphology; neuronal subtypes; oxytocin; zebrafish

\section{Introduction}

Oxytocin (Oxt; formerly isotocin) is exclusively produced by a small group of neurons in the zebrafish preoptic hypothalamus (Herget et al., 2014), yet it regulates diverse evolutionarily conserved functions. Neurons producing Oxt in the rat are activated during stress or feeding, and Oxt is involved in analgesia and energy metabolism (Lee et al., 2009; Onaka et al., 2012; Eliava et al., 2016). Oxt's most prominent role is the regulation of social behavior and reproduction, including conspecific recognition, pair bonding, fear and trust regulation, mother-child attachment, parturition, and lactation in mammals (Pedersen and Prange, 1979; Kendrick et al., 1987; Lee et al., 2009; Onaka et al., 2012). Its prominent social regulatory role is further supported by its potential involvement in the impairment of social interaction in autism spectrum disorders in humans (Meyer-Lindenberg et al., 2011).

Received September 12, 2016; accepted December 14, 2016; First published January 16, 2017.

The authors declare no competing financial interests.

Author contributions: U.H. and S.R. designed research; U.H. and O.S.T. performed research; J.A.G.T. and B.K. contributed unpublished transgenic tools; U.H. and O.S.T. analyzed data; U.H., S.R., and J.A.G.T. wrote the paper.

This work was supported by the Max Planck Society, the University Medical Center of the Johannes Gutenberg University Mainz, and the German federal office for education and research (Bundesministerium für Bildung und Forschung) grant number 01GQ1404 to S.R.

J.A. Gutierrez-Triana's current address: Centre for Organismal Studies, University of Heidelberg, Im Neuenheimer Feld 230, 69120 Heidelberg, Germany.

Acknowledgments: We thank Regina Singer for assistance with injections. We are grateful to Benjamin Lohrer for assistance with injections, stainings, and reconstructions. We also thank Rodrigo De Marco, Colette vom BergMaurer, and Stephanie Preuss for helpful discussions throughout the course of this work. We thank Regina Singer, Gabi Shoeman, and Angelika Schoell for technical assistance and expert fish care. The Brainbow plasmid used to generate our constructs was kindly provided by Jean Livet. We are grateful to Erin Schuman and Colette vom Berg-Maurer for critical reading and helpful comments on the manuscript.

Correspondence should be addressed to Soojin Ryu, Focus Program Translational Neuroscience, University Medical Center, Johannes Gutenberg University Mainz, Langenbeckstr. 1, 55131 Mainz, Germany. E-mail: soojin.ryu@unimedizin-mainz.de.

U. Herget's current address: Division of Biology and Biological Engineering, California Institute of Technology, Pasadena, CA 91125, USA.

DOI:http://dx.doi.org/10.1523/ENEURO.0278-16.2016

Copyright $\odot 2017$ Herget et al.

This is an open-access article distributed under the terms of the Creative Commons Attribution 4.0 International, which permits unrestricted use, distribution and reproduction in any medium provided that the original work is properly attributed.
Oxt is produced in the paraventricular (PVN) and supraoptic nuclei of the mammalian hypothalamus and transported through axons toward the neurohypophysis, the neuronal posterior lobe of the pituitary, where it is released into the body circulation (Brownstein et al., 1980). Oxt is also transported and released within the brain, probably via two different delivery modes: local dendritic release followed by slow diffusion (Ludwig and Leng, 2006) and fast targeted axonal release in distant regions widely spread throughout the brain (Buijs, 1978; Sofroniew, 1980; Swanson and Hartman, 1980; Knobloch et al., 2012). For example, Oxt originating from rat hypothalamic cells is axonally delivered to forebrain regions including the central amygdala, where Oxt mediates fear suppression (Knobloch et al., 2012). Such Oxttransporting projections have also been suggested in voles and mice (Ross et al., 2009; Dölen et al, 2013). Recent observations in rats also suggest mutual innervation of oxytocinergic cells within and across hemispheres (Eliava et al., 2016).

Despite these advances, it is not well understood how central and peripheral functions of Oxt are coordinated. Some studies demonstrated that magnocellular Oxt neurons of the neurohypophyseal system feature collaterals reaching into the striatum or central amygdala (Ross et al., 2009; Knobloch et al., 2012). Some oxytocinergic cells were recently demonstrated to have a dual analgesic function in rats, innervating other neuroendocrine oxytocinergic cells to release Oxt into the blood, while simultaneously inhibiting nociception by long-range collateral fibers reaching into the dorsal horn of the lumbar spinal cord (Eliava et al., 2016). Although a dichotomic separation of PVN projections reaching toward either the pituitary or the medulla and spinal cord was suggested before (Hosoya and Matsushita, 1979; Swanson and Kuypers, 1980), conflicting data were reported in fish (separate projection cell types in the plainfin midshipman, Goodson et al., 2003; dual projections of the same cells in the trout, Saito et al., 2004). The situation in the developing zebrafish brain is unknown. An important and currently open question is whether distinct Oxt neuron subtypes exist in zebrafish that mediate specific central or peripheral functions. To address this question, a large number of Oxtpositive cells must be sampled, and individual Oxt cells must be categorized based on distinguishable features.

With a simpler transparent brain and genetic access, zebrafish larvae offer significant experimental advantages 
for structural and functional analysis of individual neurons. Importantly, zebrafish larvae execute endocrine functions and complex behaviors within their first $5 \mathrm{~d}$ of development (Löhr and Hammerschmidt, 2011). Although the presence of tracts and projections throughout brain regions caudal to the PVN-homologous neurosecretory preoptic area (NPO) was shown before (Coffey et al., 2013; Herget et al., 2014), the morphology and target regions of individual oxytocinergic neurons have remained unclear.

In this study, we used zebrafish larvae to characterize the morphology and projection targets of neurons producing Oxt. To distinguish individual cells within the dense cluster and fiber bundles, we targeted Brainbow (Livet et al., 2007; Lichtman et al., 2008) to the NPO (Herget et al., 2014) of 6-d-old zebrafish larvae using both an oxt promoter (Coffey et al., 2013) and a conserved regulatory element of the transcription factor orthopedia a (otpa; Gutierrez-Triana et al., 2014). Random recombination of the Brainbow cassette by inducible Cre recombinase allowed spectral separation of individual cells and their projections from their densely intermingled neighbors. Morphological whole-cell 3D skeletonization revealed a striking structural diversity and multiple target regions of Oxt-producing neurons in the larval zebrafish. Registration of skeletonized cells into one common model brain showed a separation of the oxytocinergic cluster into two distinct groups: a rostral hypophysiotropic cluster and a caudal encephalotropic cluster, indicating that in zebrafish, peripheral neuroendocrine and different central neuromodulatory processes are likely mediated by dedicated oxytocinergic pathways.

\section{Methods}

\section{Fish maintenance}

Maintenance and breeding of male and female $A B / T L$ wild-type zebrafish were performed under standard conditions at $28.5^{\circ} \mathrm{C}$ on a $12: 12$-h light/dark cycle (Westerfield, 2000). For all experiments, crosses of $A B$ and $T L$ strains were used. All procedures were performed according to the guidelines of the German animal welfare law and approved by the local government (Regional Council, Karlsruhe, Germany).

\section{Plasmid construction}

The pST_OtpECR6:BrbM plasmid was generated by cloning the $3 \times$ multimerized NPO-regulatory region of the zebrafish gene otpa (OtpECR6) together with the E1B minimal promoter (Gutierrez-Triana et al., 2014) upstream of the membrane-bound Brainbow-1.1 (BrbM) cassette (Livet et al., 2007) in a vector containing both I-Scel and Tol2 sites. To generate pST_Oxt:BrbM, the OtpECR6 enhancer was replaced by the $1.7-\mathrm{kb}$ regulatory region of the zebrafish oxt gene, whose activity was shown to reflect the expression of endogenous oxt (Coffey et al., 2013).

\section{Generation of transgenic lines}

Recombinant plasmids were injected into one-cellstage $A B / T L$ embryos at a $15 \mathrm{ng} / \mu$ l concentration in the presence of $10 \mathrm{ng} / \mu \mathrm{l} \mathrm{Tol} 2$ transposase mRNA and $0.05 \%$ phenol red (Sigma-Aldrich, \#P3532). The progenies of injected fish were maintained in E2 medium $+0.2 \mathrm{~mm}$ $\mathrm{N}$-phenylthiourea (Sigma-Aldrich, \#P7629) to prevent pigmentation and screened for preoptic Kusabira expression at $3 \mathrm{~d}$ post-fertilization (dpf) using a Leica MZ6 fluorescence microscope. The following stable transgenic lines were established: $T g(O t p E C R 6: B r b M)^{h d 23}$ and $T g(O x t$ :

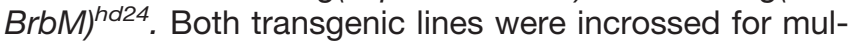
tiple generations to increase copy numbers.

\section{Brainbow induction}

For stochastic recombination of the Brainbow transgenes, one-cell-stage progenies of Tg(OtpECR6:Brb$M)^{h d 23}$ or $\operatorname{Tg}(\mathrm{Oxt}: \mathrm{BrbM})^{\text {hd } 24}$ fish were injected with hsp: nls-Cre plasmids at a concentration of $15 \mathrm{ng} / \mu \mathrm{l}$ in the presence of $10 \mathrm{ng} / \mu \mathrm{l} \mathrm{I-Scel} \mathrm{meganuclease} \mathrm{enzyme} \mathrm{and}$ $0.05 \%$ phenol red. For transient Brainbow expression, we injected one-cell-stage $A B / T L$ embryos with pST_OtpECR6:BrbM or pST_Oxt:BrbM plasmids at a concentration of $15 \mathrm{ng} / \mu \mathrm{l}$ together with $10 \mathrm{ng} / \mu \mathrm{l}$ Tol2 transposase mRNA and hsp:nls-Cre plasmid with I-Scel enzyme as described above. On the next day, injected embryos were heat-shocked at $37^{\circ} \mathrm{C}$ for $1.5-15 \mathrm{~h}$, depending on the line used and the sparseness desired.

\section{Whole-mount immunohistochemistry}

Fixation and staining were performed as reported previously (Kastenhuber et al., 2010; Herget et al., 2014), using a chicken anti-GFP antibody (Abcam, \#13970, RRID: AB_300798) together with a rabbit anti-Oxt antibody (Herget et al., 2014), and anti-chicken Alexa Fluor 488 (Invitrogen, \#11039, RRID: AB_142924) plus antirabbit Alexa Fluor 647 secondary antibodies (Invitrogen, \#A21245, RRID: AB_141775). Anatomical reference landmarks were visualized using NeuroTrace Fluorescent NissI Stain (NT; Invitrogen, \#N21480).

\section{Confocal microscopy}

For imaging, larval heads were cleared in $80 \%$ glycerol (Gerbu Biotechnik, \#2006.50000) in PBS for 1 h. Confocal stacks were recorded using a Leica SP5 confocal microscope with a $20 \times$ glycerol objective. Live imaging was performed on agarose-embedded larvae (Low Melt Agarose, Carl Roth, \#6351.1) with a $20 \times$ water objective. Each channel was recorded sequentially to reduce interfering signals from overlapping emission spectra. Zoom, dimensions, gain, offset, average, and speed were adjusted for each stack to obtain the optimal image quality of the desired volume.

\section{Image evaluation}

Stacks were evaluated using Amira 5.3 or 5.4 (FEl Visualization Sciences Group) to create maximum intensity projections and 3D voxel-rendered views and to perform 3D registration and neuron skeletonization. Maximum intensity projections and voxel-rendered views were restricted to the volume of interest. Brightness and contrast were adjusted for each channel. Neuron skeletonization was performed using the SkeletonTree plugin (Schmitt et al., 2004; Evers et al., 2005). Stacks of differ- 

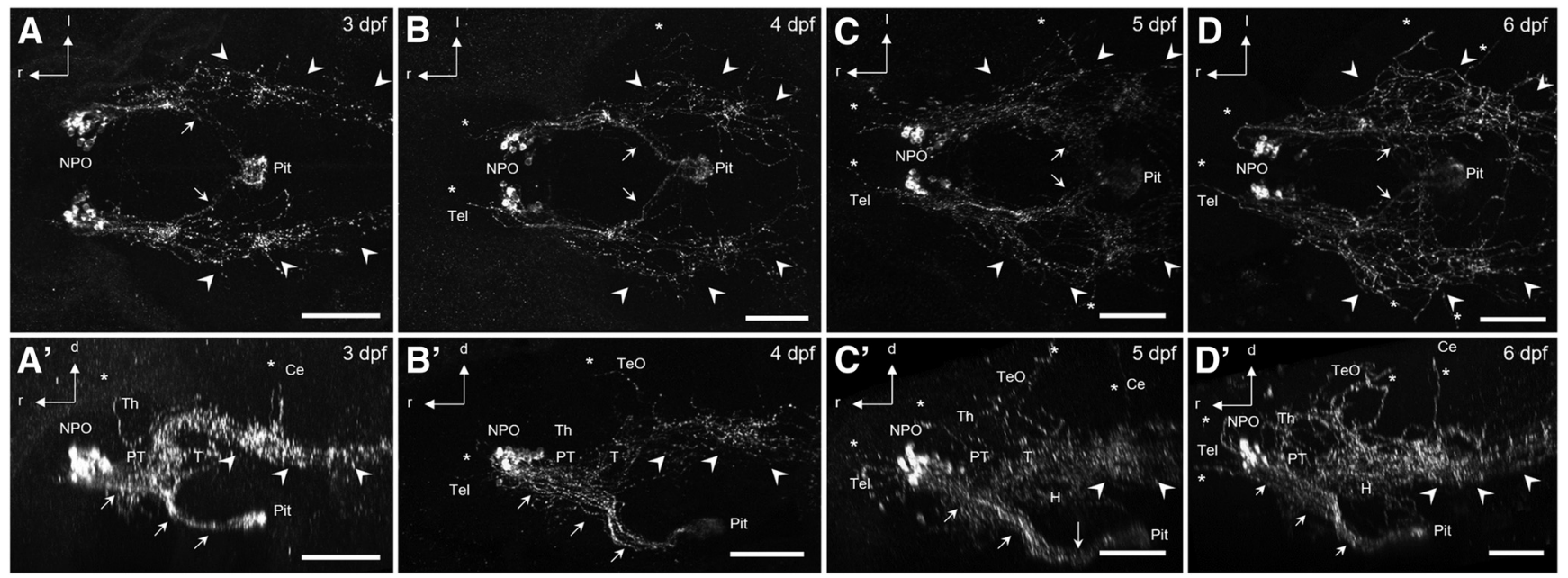

Figure 1. Projections of Oxt-positive cells in the NPO of developing zebrafish. Dorsal $(\boldsymbol{A}-\boldsymbol{D})$ and lateral $\left(\boldsymbol{A}^{\prime}-\boldsymbol{D}^{\prime}\right)$ views of immunostained Oxt-positive cells and their projections. Note the complexity of projections reaching toward the pituitary (arrows), the spinal cord (arrowheads), and other brain regions (asterisks). Pituitary and spinal projections are established at $3 \mathrm{dpf}(n=9)$, whereas additional innervation of other brain regions forms over $4(n=11)$ and $5(n=13)$ dpf and is established by $6 \mathrm{dpf}(n=24)$. Scale bars: 100 $\mu \mathrm{m}$. d, dorsal (following body axis); H, hypothalamus; I, lateral; Pit, pituitary; PT, posterior tuberculum; r, rostral (following body axis); T, tegmentum; Th, thalamus.

ent animals were manually registered by transformation using commonly stained cell clusters as references.

\section{Results}

\section{Complex oxytocinergic projections are present during early development in larval zebrafish}

Because of the successive specialization of Oxt functions during evolution, ascending Oxt projections are thought to be a feature of more advanced and mature vertebrates (Knobloch and Grinevich, 2014). To determine the extent of Oxt projection complexity in developing larvae, we used a custom-made Oxt antibody (Herget et al., 2014) to characterize the development of Oxt projection patterns in larvae at 3-6 dpf. In larval zebrafish, oxytocinergic somata are restricted to the NPO (Fig. 1 and Herget et al., 2014). Their projections form densely entangled bundles innervating the pituitary, but also reach into other brain regions and toward the spinal cord (Fig. 1). Strikingly, distinct fibers can be observed reaching into the optic tectum (TeO), the hypothalamus, and the telencephalon (Tel) at these early developmental stages. Hypophyseal and spinal projections can be observed from 3 dpf on (Fig. $1 A, A^{\prime}$ ), whereas other brain regions are innervated beginning at $4-5 \mathrm{dpf}\left(\right.$ Fig. $\left.1 B-C^{\prime}\right)$. The innervation patterns observed by $6 \mathrm{dpf}\left(\right.$ Fig. $\left.1 D, D^{\prime}\right)$ remain stable until at least $8 \mathrm{dpf}$ (data not shown). Target regions were identified using NT as a cytoarchitectural marker of brain anatomy (Fig. 2). In 6 dpf larvae, oxytocinergic fibers were found reaching into the Tel close to the anterior commissure (Fig. $2 A, B^{\prime}$ ), crossing through the postoptic commissure (Fig. $2 A$ ), prominently innervating the pituitary via the hypothalamohypophyseal tract (Fig. 2A, $B^{\prime \prime \prime}$ ), passing through major parts of the thalamus, tegmentum, and hypothalamus (Fig. $\left.2 A, B^{\prime}, B^{\prime \prime}\right)$, reaching dorsally up into the $\mathrm{TeO}$ (Fig. $2 A-B^{\prime}$ ), or passing ventrally through the medulla oblongata (Fig. 2A). Dense collateral branching occurs in the medulla oblongata, whereas only few unbranched fibers appear to run laterally parallel to the spinal cord, and therefore potentially within the putative sympathetic trunk (data not shown). Generally, Oxt immunostaining showed regional interindividual variability at this developmental stage, especially for the branches reaching into the $\mathrm{TeO}$ and the cerebellum (Ce; Fig. 3).

\section{The Brainbow technique allows morphological reconstruction of individual oxytocinergic neurons and their fibers}

An immediate question raised by the complex arrangement of oxytocinergic fiber bundles is which soma connects to which brain region. This dense network of fibers can be dissected only by single-cell reconstruction. To visualize individual Oxt neurons in their entirety, we used the Brainbow technique to achieve multicolor labeling of the entire oxytocinergic neuron population. We used two independent transgenic approaches. We began by using Brainbow driven by a promoter covering the NPO (Gutierrez-Triana et al., 2014), and later also used an Oxt promoter which restricts the Brainbow expression to mostly oxytocinergic cells (Coffey et al., 2013). We achieved Brainbow expression in the NPO (Fig. 4A) by linking BrbM to the otpECR6 promoter, a conserved regulatory element of the transcription factor otpa, which allows genetic targeting of a part of the NPO covering corticotropin-releasing hormone (crh), arginine vasopres$\sin (a v p)$, and oxt-positive cells (Gutierrez-Triana et al., 2014). The established Brainbow line, Tg(OtpECR6:BrbM), can be used to distinguish the innervation targets of different NPO cells, as illustrated by differently colored cells projecting to different neurohypophyseal subregions (Fig. 4A). Because Brainbow is expressed throughout the NPO and therefore covers neighboring and intermingled cell types as well, immunohistochemistry $(\mathrm{IHC})$ was car- 

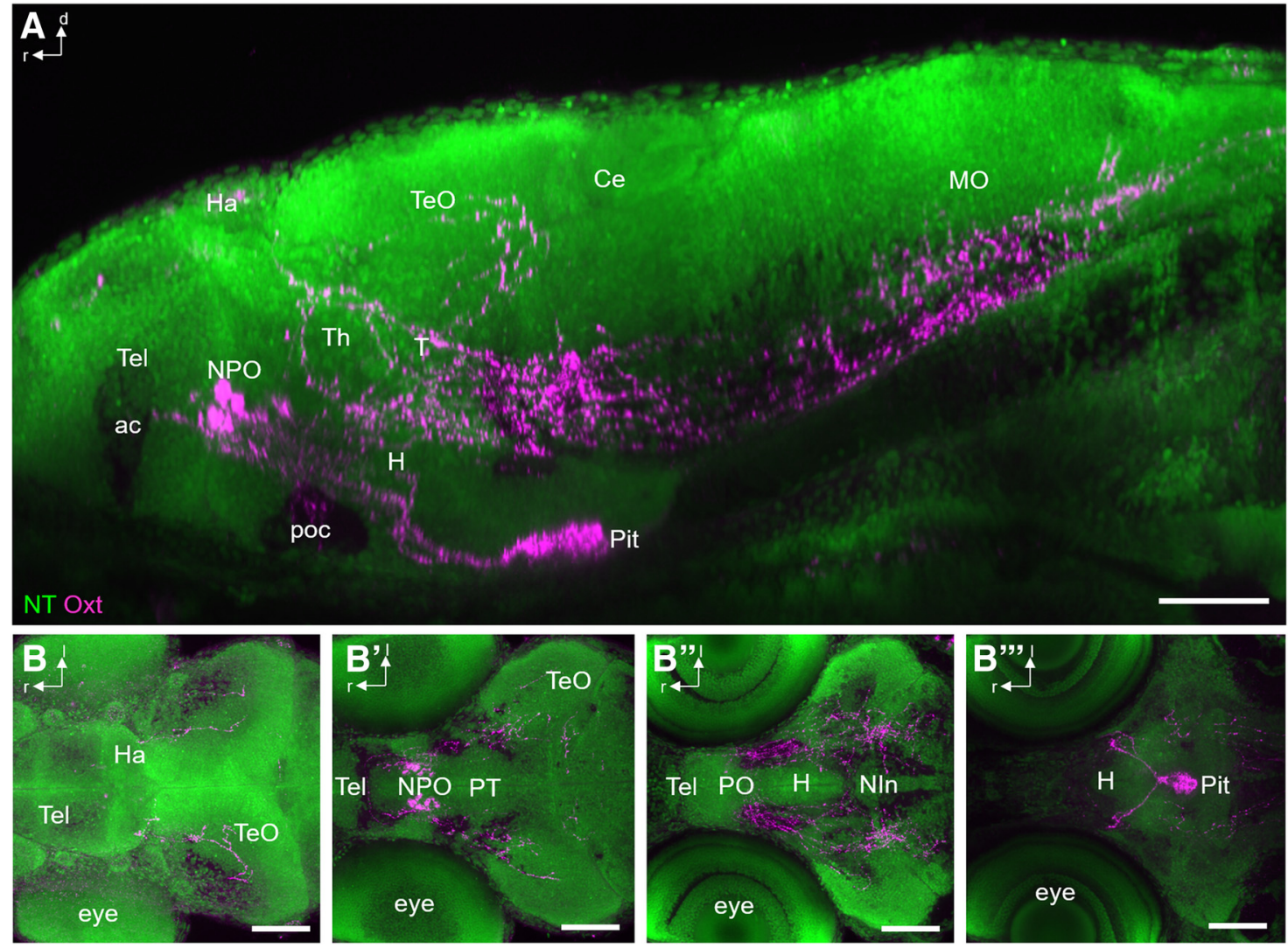

Figure 2. Innervated regions of Oxt-positive neurons at $6 \mathrm{dpf}$. $\boldsymbol{A}$, Lateral view of immunostained Oxt-carrying fibers (magenta) in combination with NT (green) to identify brain regions at $6 \mathrm{dpf}(n=12)$. Fibers reach the pituitary through the hypothalamohypophyseal tract, but also innervate the caudal Tel and TeO. Spinal projections pass the metencephalon and myelencephalon ventrally. $\boldsymbol{B}-\boldsymbol{B}^{\prime \prime}$, Serial horizontal substacks (dorsal to ventral) show innervation of the TeO (B), the caudal Tel $\left(\boldsymbol{B}^{\prime}\right)$, hypothalamic and tegmental regions $\left(\boldsymbol{B}^{\prime \prime}\right)$, and the pituitary $\left(\boldsymbol{B}^{\prime \prime \prime}\right)$. The fibers mostly traverse within Nissl-negative regions, which correspond to white matter. Scale bars: 100 $\mu \mathrm{m}$. ac, anterior commissure; Ha, habenula; MO, medulla oblongata; NIn, interpeduncular nucleus; poc, postoptic commissure.

ried out using the Oxt antibody together with an anti-GFP antibody (to detect recombined BrbM fluorescent proteins) to confirm oxytocinergic identity. Comparing confocal images taken in vivo with images of the same animal after fixation and staining reveals fibers carrying the peptide labeled by $\mathrm{IHC}$ (Fig. $4 B, B^{\prime}$ ). IHC also greatly improves the fluorescence signal and reduces the background, facilitating visualization of fibers in deep regions such as the pituitary. In addition to $\mathrm{Tg}$ (OtpECR6: BrbM), we generated $T g(O x t: B r b M)$ using a published oxt promoter (Coffey et al., 2013), which is more specific for oxytocinergic cells. IHC confirmation of oxytocinergic identity was nevertheless also performed in experiments using this oxt promoter to ensure that only oxytocinergic cells were processed further for reconstruction. We also used animals that transiently expressed Brainbow (for higher expression levels at the expense of color diversity). The morphology of nonoverlapping cells identified as Oxt-positive by IHC was reconstructed using Amira (Fig. $4 C-C^{\prime \prime}$ ). Several selection steps excluded animals from further processing (Fig. 4D). We often observed expression of the same fluorophore in neighboring cells or induction of Brainbow in fibers not carrying Oxt, and such animals were excluded from morphological analysis. Only those ani- mals displaying successful recombination in cells positive for Oxt that were separated from other costained cells allowed the reconstruction of individual oxytocinergic neurons and their projections. Cases in which a cell was partially but not completely reconstructable were excluded from further morphological analysis but included in soma position analysis.

\section{Morphological analysis of oxytocinergic cells reveals two major types based on their projection patterns}

Using the Brainbow approach, we characterized the morphological diversity and projection targets of 6-dpf oxytocinergic cells and found diverse projection patterns that can be categorized into two distinct groups: some neurons innervate the pituitary, and others instead innervate other brain regions. Oxt-positive cells innervating the pituitary are comparatively simple, featuring only a single projection toward the pituitary, or very limited branching near the soma within the NPO (Fig. 5), which occasionally extends caudally (Fig. $5 C, C^{\prime}$; putative posterior tuberculum or rostral hypothalamus). Other hypophysiotropic cells feature more complex proximal branching within the NPO (Fig. $6 A-G^{\prime}$ ), which often extends caudally (Fig. $6 B$, $B^{\prime}, D, D^{\prime}, F, F^{\prime}, G, G^{\prime}$; putative posterior tuberculum or rostral hypothalamus). The somata and projections of 

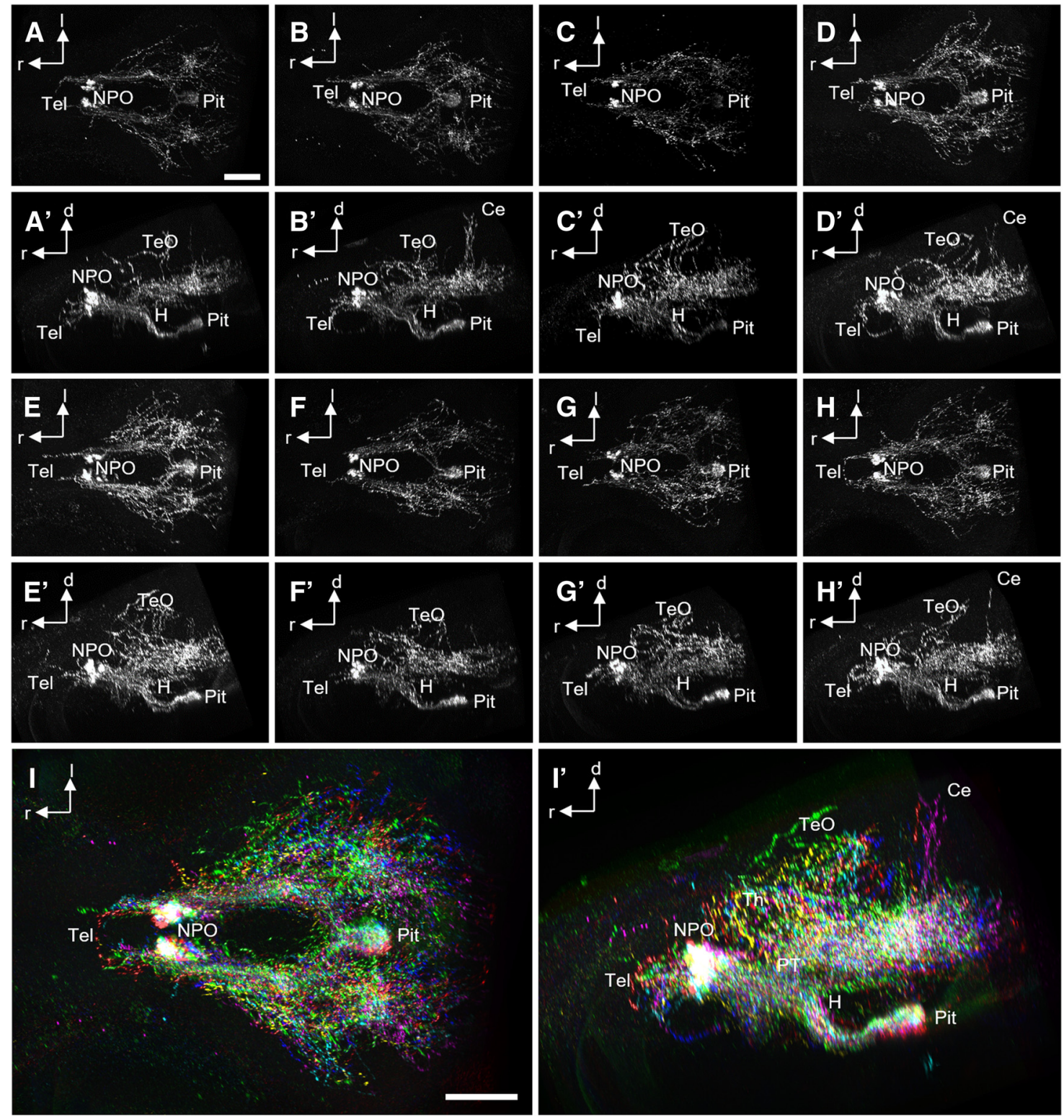

Figure 3. Variable Oxt-positive projections at $6 \mathrm{dpf}$. $\boldsymbol{A}-\boldsymbol{H}^{\prime}$, Oxytocinergic cells and their innervation patterns shown by IHC in eight different animals, dorsal $(\boldsymbol{A}-\boldsymbol{H})$ and lateral $\left(\boldsymbol{A}^{\prime}-\boldsymbol{H}^{\prime}\right)$ views. $\boldsymbol{I}, \boldsymbol{I}^{\prime}$, The same data after 3D registration of all stacks into one common model, dorsal $(\boldsymbol{I})$ and lateral $\left(I^{\prime}\right)$ views. Each stack is shown with a different color. Note the variability of innervation patterns. Some animals show oxytocinergic innervation of the $\mathrm{Ce}$, and tectal branches appear to be somewhat different in each individual. Scale bars: $100 \mu \mathrm{m}$.

these two subcategories do not segregate after registration (Fig. 6H; see also below).

Apart from pituitary-innervating cells, broad branching throughout the brain was observed for other Oxt-positive neurons (Figs. 7 and 8). Projections of some cells reached rostrally into the Tel and other brain regions, but not the pituitary (Fig. 7). These cells feature extensive branching throughout the brain, with fibers reaching rostrally into the Tel (Fig. 7A-E' ), caudoventrally into the hypothalamus (Fig. $7 A-C^{\prime}, E-E^{\prime}$ ), caudodorsally into the TeO (Fig. $\left.7 C-D^{\prime}\right)$, and branches crossing to the contralateral hemisphere (Fig. 7A, $A^{\prime}, C-E^{\prime}$; registration in $F$ ). Other encephalotropic cells did not reach into the Tel or toward the pituitary, but into other brain regions (Fig. 8). These cells featured projections reaching dorsally into the prethala- mus (Fig. $8 A, A^{\prime}$ ), caudoventrally into the hypothalamus (Fig. $8 B-I^{\prime}$ ), caudodorsally into the Ce (Fig. 8D, $D^{\prime}$ ) and the TeO (Fig. 8G-l' ), and branches crossing to the contralateral hemisphere (Fig. $8 B, B^{\prime}, E-I$; registration in $J$ ). Strikingly, we never observed Oxt cells that projected to both the brain and the pituitary. Therefore, these two projection types are mutually exclusive and occur in different cells.

\section{Neuroendocrine and neuromodulatory clusters exhibit anatomical separation}

To determine whether Oxt cells that exhibit the two projection types show anatomical clustering, we visualized the cell bodies and projection patterns of groups of cells. We manually registered reconstructed cells by 3D 

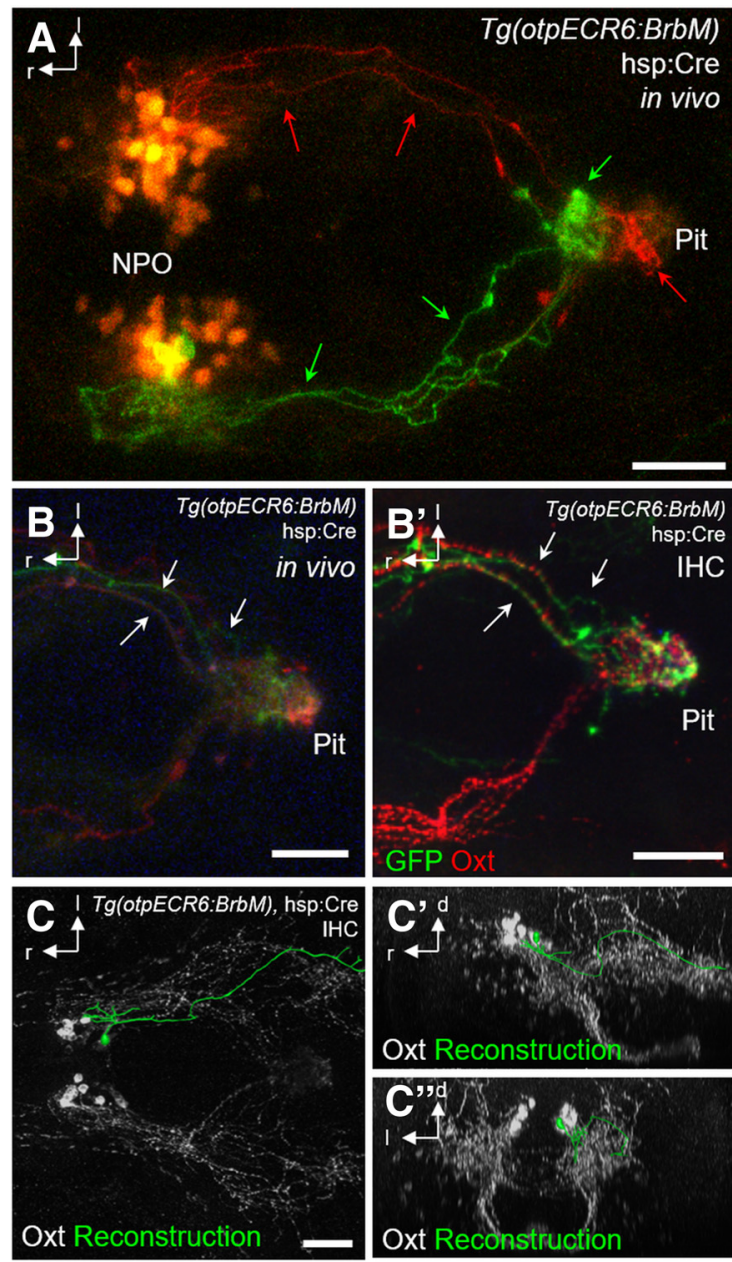

Figure 4. NPO Brainbow in larval zebrafish. $\boldsymbol{A}$, Different colors resulting from recombination distinguish different projections and target regions (arrows) of NPO cells towards the pituitary at $5 \mathrm{dpf}$, which would be unrecognizable with only one color. Scale bars:

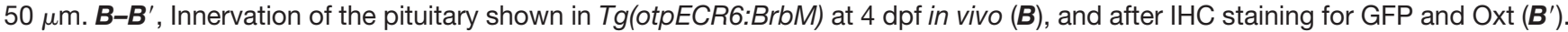
Note that features of the projections visible in vivo can also be identified after fixation and staining (arrows). $\boldsymbol{C}_{-} \boldsymbol{C}^{\prime \prime}$, Reconstructed morphology of an Oxt-positive cell resulting from Brainbow recombination (green), shown together with Oxt IHC (white) in dorsal (C), lateral $\left(\boldsymbol{C}^{\prime}\right)$, and frontal views $\left(\boldsymbol{C}^{\prime \prime}\right)$. This cell projects toward the spinal cord. $\boldsymbol{D}$, Methodological pipeline. One-cell-stage embryos $(n>$ $5,000)$ were injected and subjected to a heat shock on the next day to induce Cre recombinase. The surviving embryos $(\sim 3,500)$ were fixed at the relevant stage and immunostained to confirm peptidergic cell type identity. Brainbow recombination was displayed in 181 animals, and recombination occurred in oxytocinergic cells in 119 animals, covering a total of 216 Oxt-positive cells. This subset of animals showing successful recombination in oxytocinergic cells was used for single-cell skeletonization. Cells that could not be completely reconstructed with certainty were discarded, so eventually 26 animals were used for the reconstructions presented. Reconstructed cells were registered using common landmarks. Note that each selection step excludes animals from further processing, requiring a large starting number to get few cell reconstructions and resulting in overall low efficiency. Scale bars: $50 \mu \mathrm{m}$.

transformation using both the residual Kusabira signal of unrecombined Brainbow and the costained peptide IHC labeling in the NPO and the pituitary as reference landmarks. This allowed the visualization of multiple cells within the same model brain (Fig. 9; see also Figs. $6 H, 7 F$, and $8 \mathrm{~J}$ ). The trajectory of axons innervating the pituitary generally follows a similar double-curved path, first turning ventrally but then curving dorsally and into the pituitary (Fig. 9A-A" ; Movie 1). In comparison, the combined group of encephalotropic cells shows a much more diverse collection of morphologies, with each cell featuring a unique innervation pattern (Fig. 9B- $B^{\prime \prime}$; Movie 2). Comparing the hypophysiotropic and encephalotropic groups of all reconstructed cells after registration revealed that the hypophysiotropic population resides in a more rostral part of the NPO, whereas the encephalotropic cells tend to be caudal to them (Fig. 10; Movie 3). This suggests an anatomical separation of these subtypes of oxytocinergic cells within the NPO.

\section{Discussion}

Oxt is thought to be delivered via different release pathways: volume transmission from hypothalamic dendrites (Ludwig and Leng, 2006) or targeted axonal longrange delivery. Our understanding of distinct innervation patterns and the circuitry of different Oxt functions has 

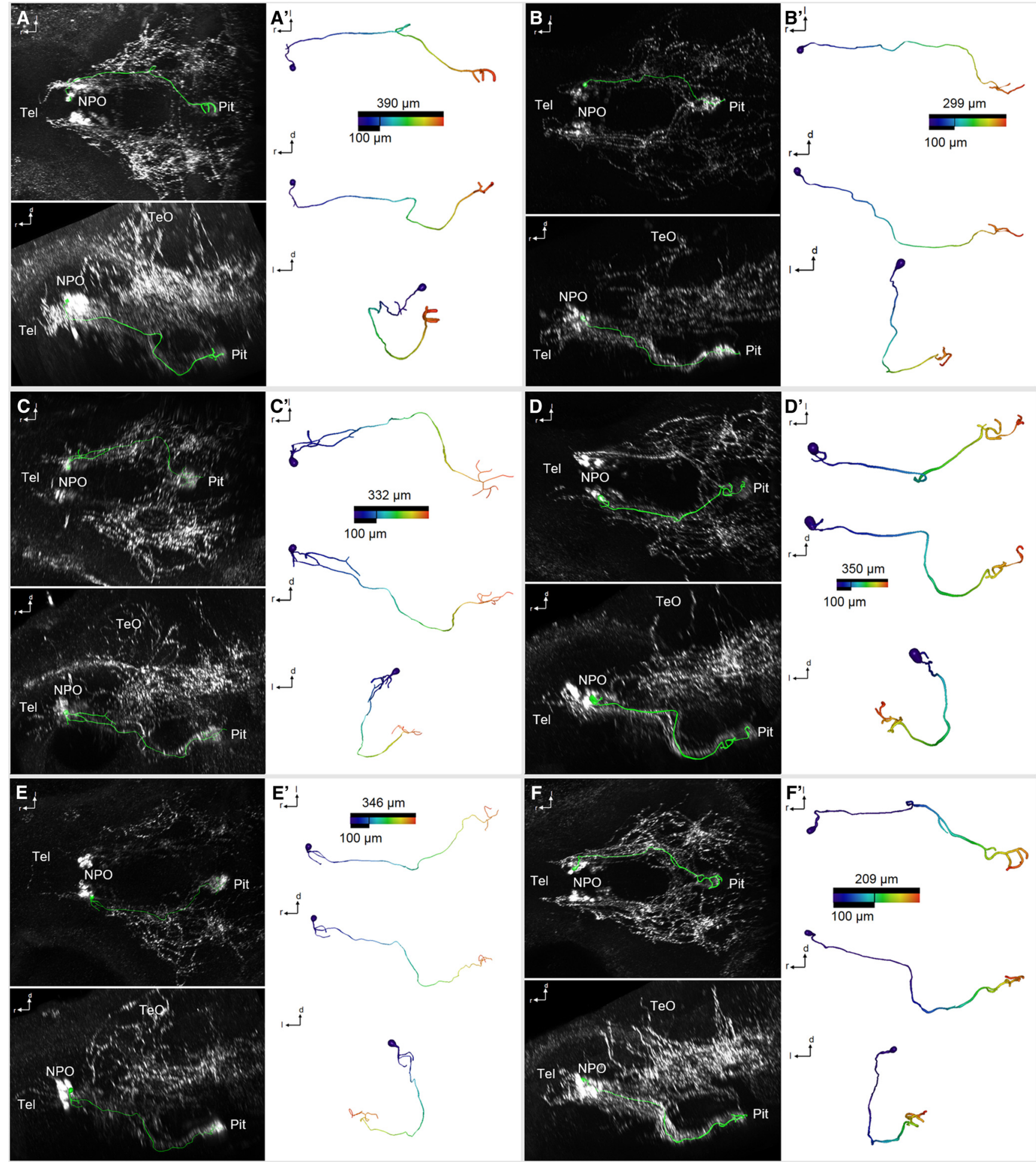

Figure 5. 3D reconstruction of morphologically simple Oxt-positive preoptic neurons that innervate the pituitary at 6 dpf. $\boldsymbol{A}-\boldsymbol{F}^{\prime \prime}$, Skeletonized neurons, shown within the context of the Oxt IHC (A-F; dorsal and lateral views), and shown individually with a color code of the distance along each branch from the soma center $\left(\boldsymbol{A}^{\prime}-\boldsymbol{F}^{\prime}\right.$; dorsal, lateral, and frontal views). Distance color codes are scaled to the maximum distance of each cell. Note that these cells feature very limited branching close to the soma, or no branching at all, until they reach the pituitary.

been rapidly increasing due to considerable recent advances using rats. Innervated brain regions were reported $>30$ years ago in rats (Buijs, 1978; Sofroniew, 1980;
Swanson and Hartman, 1980), but functionally specific circuits have been identified only in recent years (Knobloch et al., 2012; Eliava et al., 2016). 

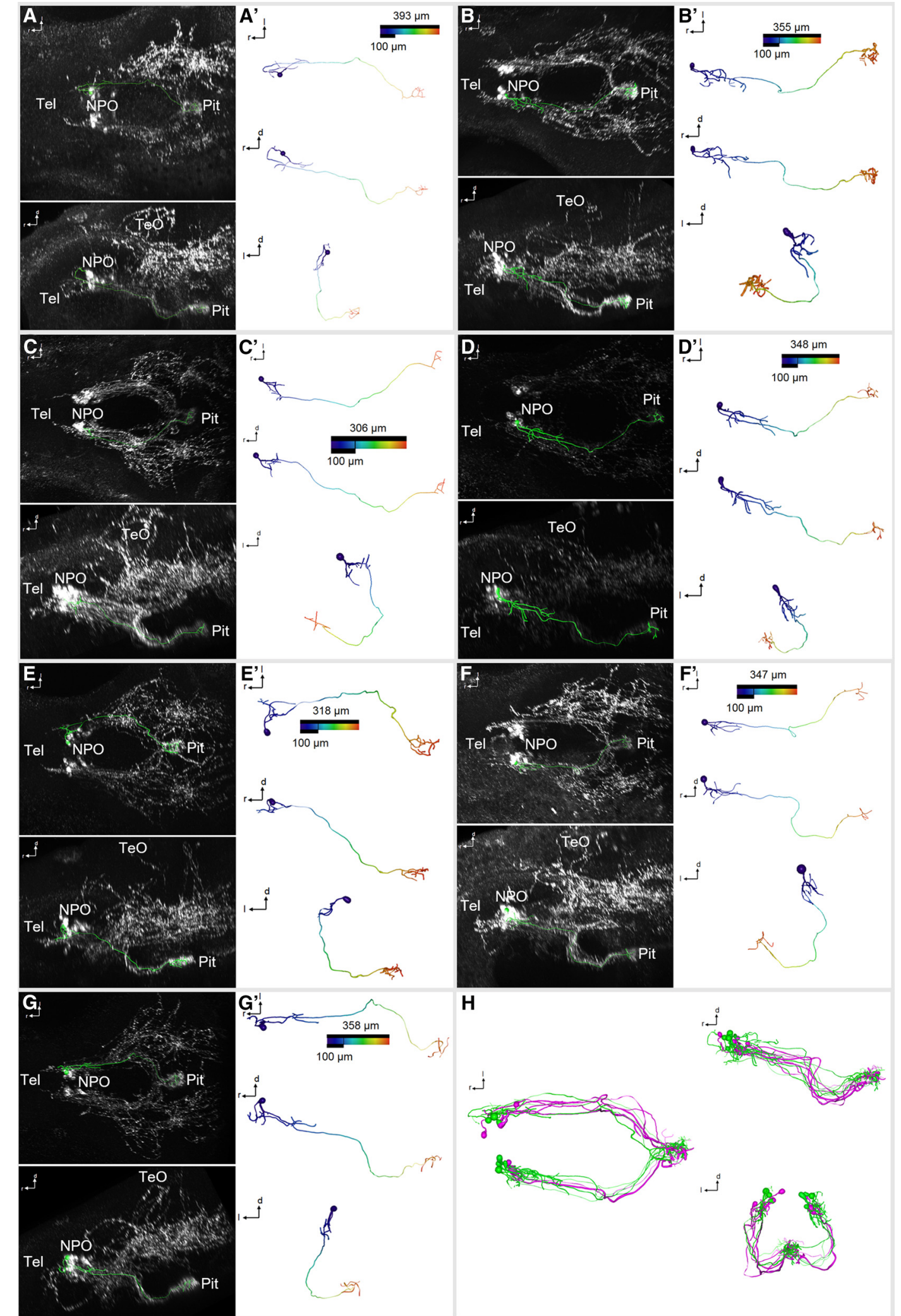

Figure 6. 3D reconstruction of morphologically complex Oxt-positive preoptic neurons that innervate the pituitary at 6 dpf. $\boldsymbol{A}-\boldsymbol{G}^{\prime \prime}$, Skeletonized neurons, shown within the context of the Oxt IHC (A-G; dorsal and lateral views), and shown individually with a color code of the distance along each branch from the soma center $\left(\boldsymbol{A}^{\prime}-\mathbf{G}^{\prime}\right.$; dorsal, lateral, and frontal views). Distance color codes are scaled to the maximum distance of each cell. Note that these cells feature several branches close to the soma. $\boldsymbol{H}, \boldsymbol{R e g i s t r a t i o n}$ of the hypophysiotropic cells shown in Fig. 5 (magenta) and Fig. 6 (green) shows intermingled projections (dorsal, lateral, and frontal views). 

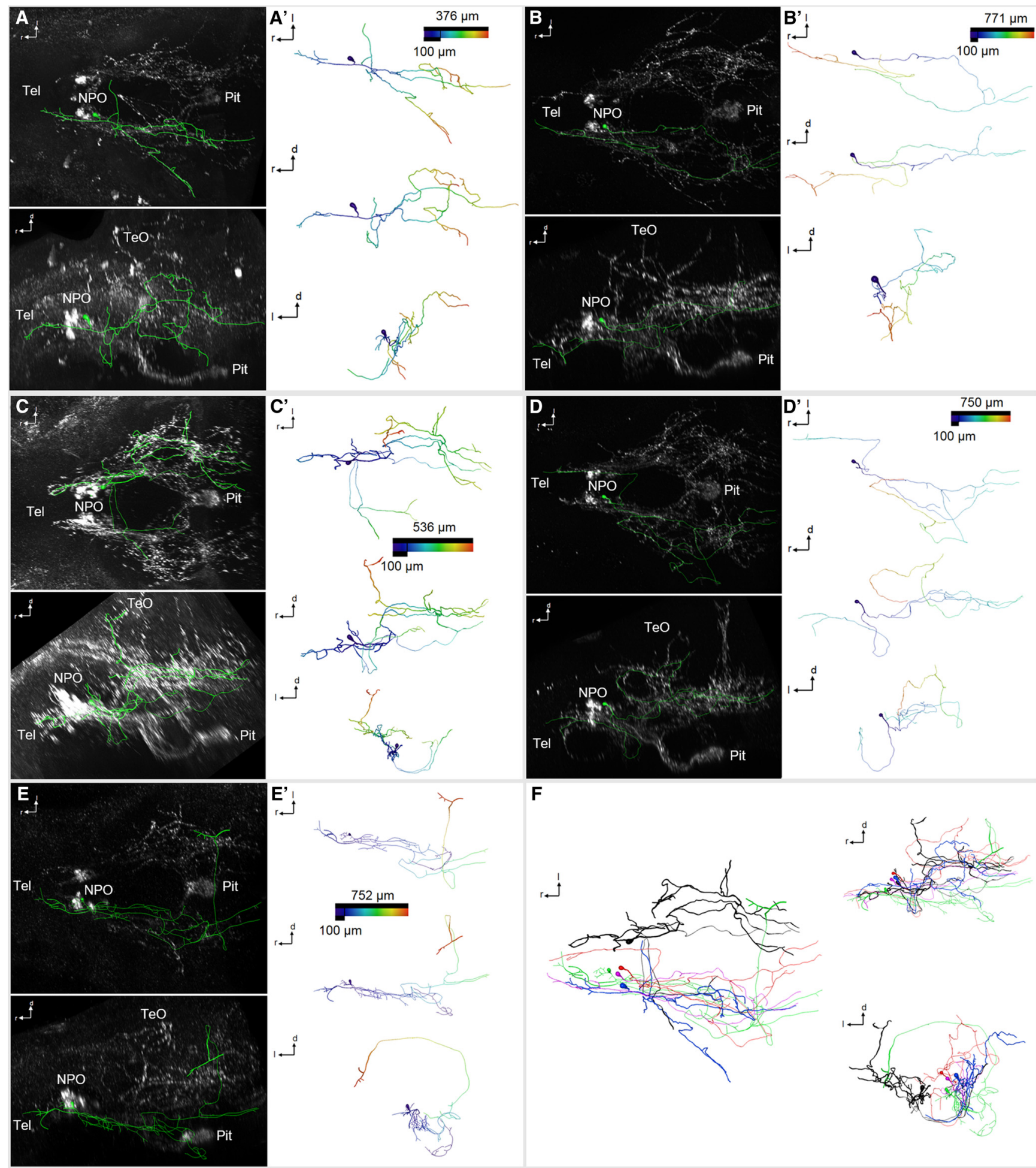

$\mathbf{F}$
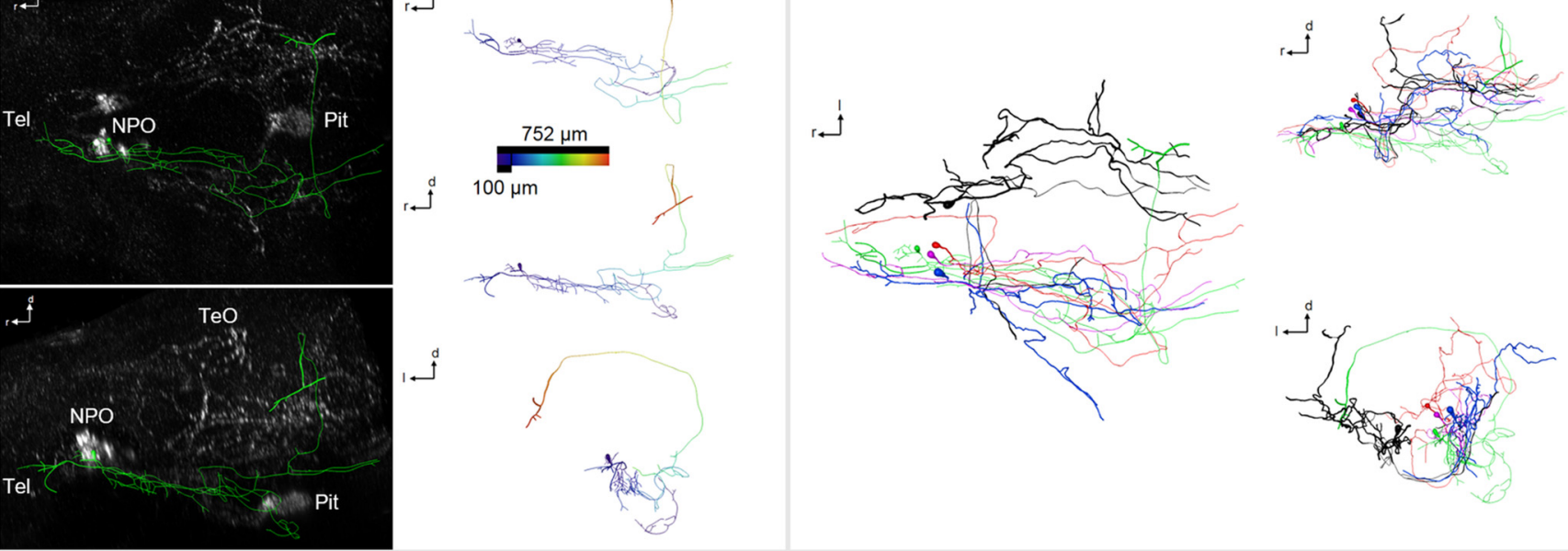

Figure 7. 3D reconstruction of Oxt-positive preoptic neurons that innervate the Tel and other brain regions, but not the pituitary, at $6 \mathrm{dpf}$. $\boldsymbol{A}-\boldsymbol{E}^{\prime \prime}$, Skeletonized neurons, shown within the context of the Oxt IHC (A-E; dorsal and lateral views), and shown individually with a color code of the distance along each branch from the soma center ( $\boldsymbol{A}^{\prime}-\boldsymbol{E}^{\prime}$; dorsal, lateral, and frontal views). Distance color codes are scaled to the maximum distance of each cell. Note that these cells feature extensive branching throughout the brain, with fibers reaching rostrally into the Tel $\left(\boldsymbol{A}-\boldsymbol{E}^{\prime}\right)$, caudoventrally into the hypothalamus $\left(\boldsymbol{A}-\boldsymbol{C}^{\prime}, \boldsymbol{E}-\boldsymbol{E}^{\prime}\right)$, caudodorsally into the TeO $\left(\boldsymbol{C}-\boldsymbol{D}^{\prime}\right)$, and several of the branches crossing to the contralateral hemisphere $\left(\boldsymbol{A}-\boldsymbol{A}^{\prime}, \boldsymbol{C}-\boldsymbol{E}^{\prime}\right)$. $\boldsymbol{F}$, Registration of these encephalotropic cells shows the contribution of each cell to the brainwide innervation pattern (dorsal, lateral, and frontal views). 

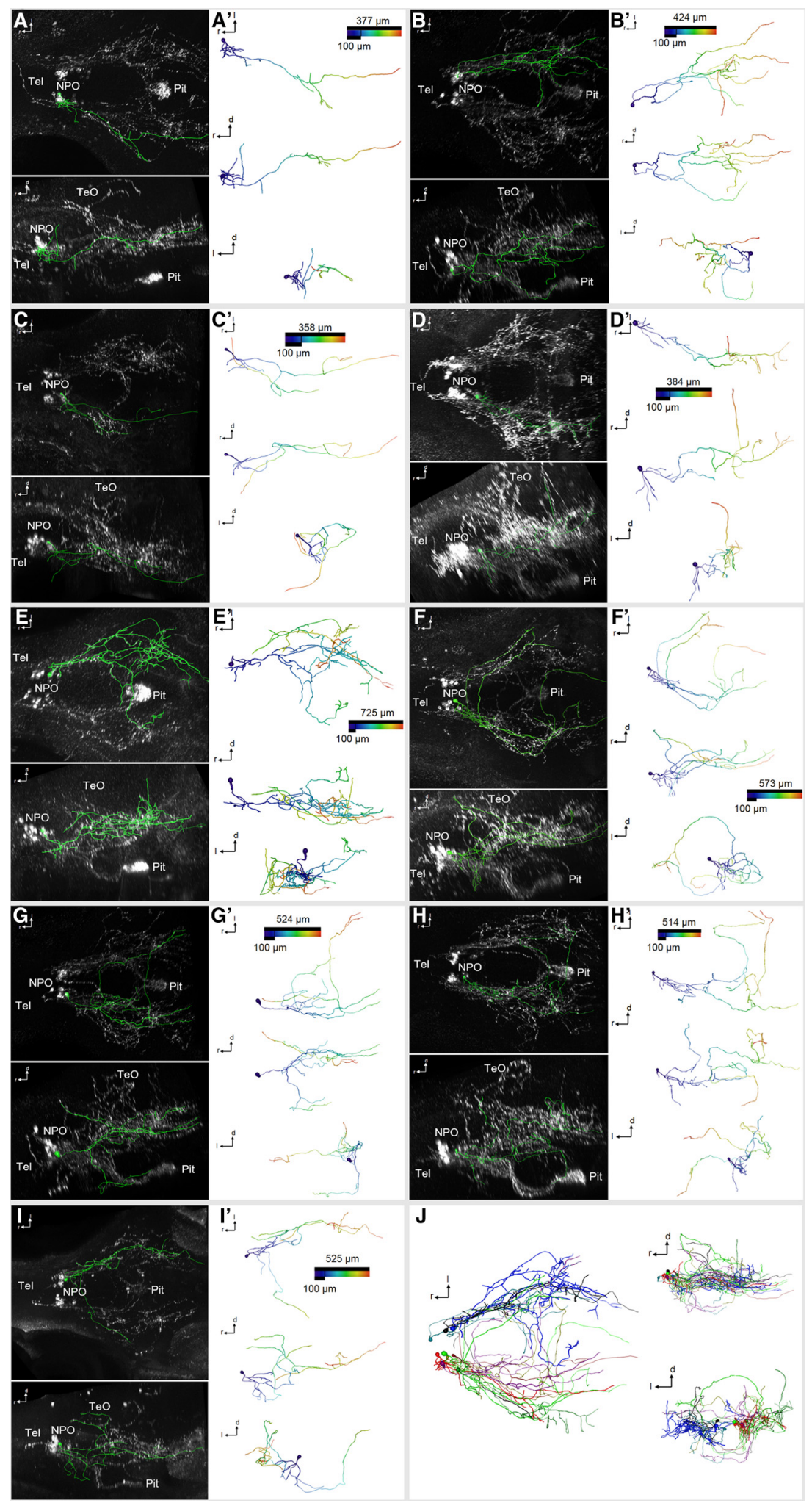

Figure 8. 3D reconstruction of Oxt-positive preoptic neurons that innervate other brain regions at 6 dpf. $\boldsymbol{A}-\boldsymbol{I}^{\prime}$, Skeletonized neurons, shown within the context of the Oxt IHC (A-I; dorsal and lateral views), and shown individually with a color code of the distance along each branch from the soma center $\left(\boldsymbol{A}^{\prime}-\boldsymbol{I}^{\prime}\right.$; dorsal, lateral, and frontal views). Distance color codes are scaled to the maximum distance of each cell. Note that these cells feature extensive branching throughout the brain, with fibers reaching dorsally into the prethalamus $\left(\boldsymbol{A}, \boldsymbol{A}^{\prime}\right)$, caudoventrally into the hypothalamus $\left(\boldsymbol{B}-\boldsymbol{I}^{\prime}\right)$, caudodorsally into the $\mathrm{Ce}\left(\boldsymbol{D}, \boldsymbol{D}^{\prime}\right)$ and the TeO $\left(\boldsymbol{G}-\boldsymbol{I}^{\prime}\right)$, and several of the branches crossing to the contralateral hemisphere $\left(\boldsymbol{B}, \boldsymbol{B}^{\prime}, \boldsymbol{E}-\boldsymbol{I}^{\prime}\right)$. $\boldsymbol{J}$, Registration of these encephalotropic cells shows the contribution of each cell to the brainwide innervation pattern (dorsal, lateral, and frontal views). 


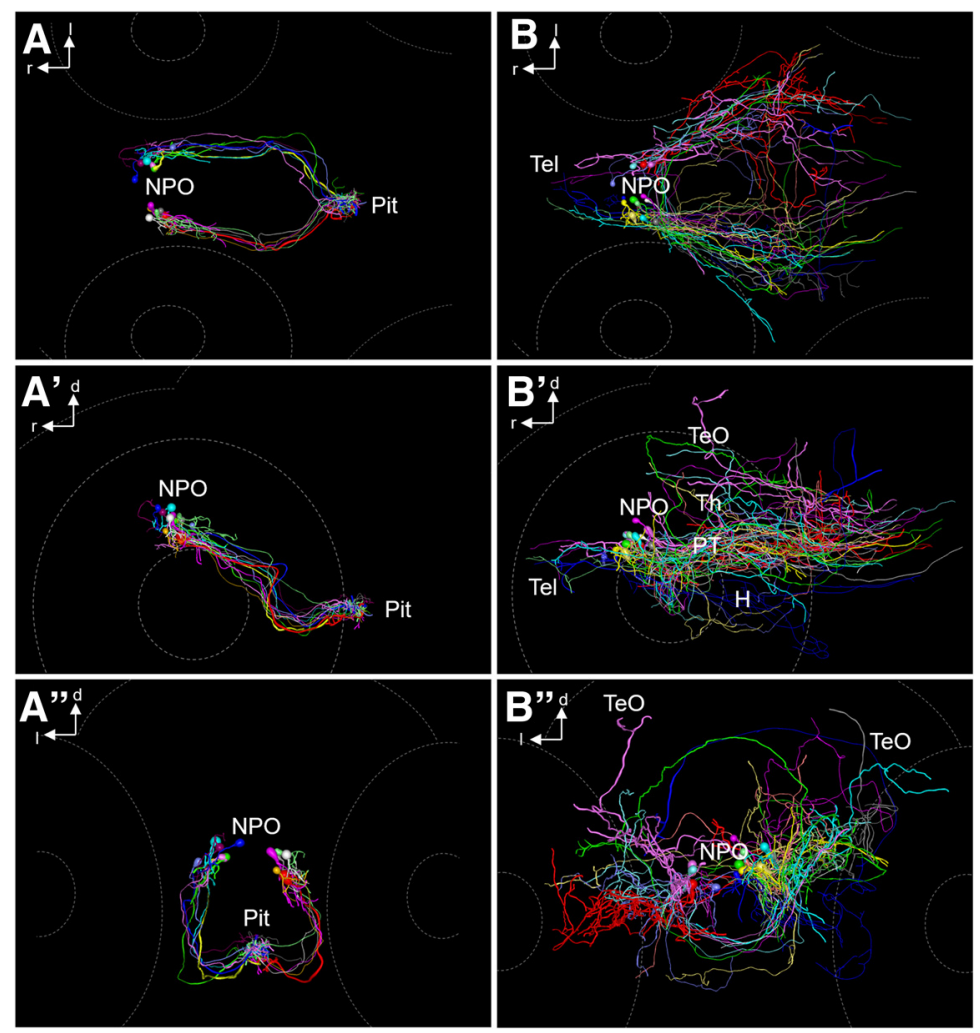

Figure 9. Projections of Oxt-positive cells manually registered from different $6 \mathrm{dpf}$ animals into one common model. $\boldsymbol{A}-\boldsymbol{A}^{\prime \prime}$, Oxt-positive cell morphology innervating the pituitary, dorsal $(\boldsymbol{A})$, lateral $\left(\boldsymbol{A}^{\prime}\right)$, and frontal $\left(\boldsymbol{A}^{\prime \prime}\right)$ views. Each cell is shown with a different color. A 3D rotation of this dataset is provided as Movie 1. $\boldsymbol{B}-\boldsymbol{B}^{\prime \prime}$, Oxt-positive cell morphology innervating regions other than the pituitary, dorsal $(\boldsymbol{B})$, lateral $\left(\boldsymbol{B}^{\prime}\right)$, and frontal $\left(\boldsymbol{B}^{\prime \prime}\right)$ views. Each cell is shown with a different color. A $3 D$ rotation of this dataset is provided as Movie 2.

The subgroup of oxytocinergic neurons featuring projections to distant brain regions is thought to be anatomically distinct from hypophysiotropic neurons (Hosoya and Matsushita, 1979; Swanson and Kuypers, 1980), leading

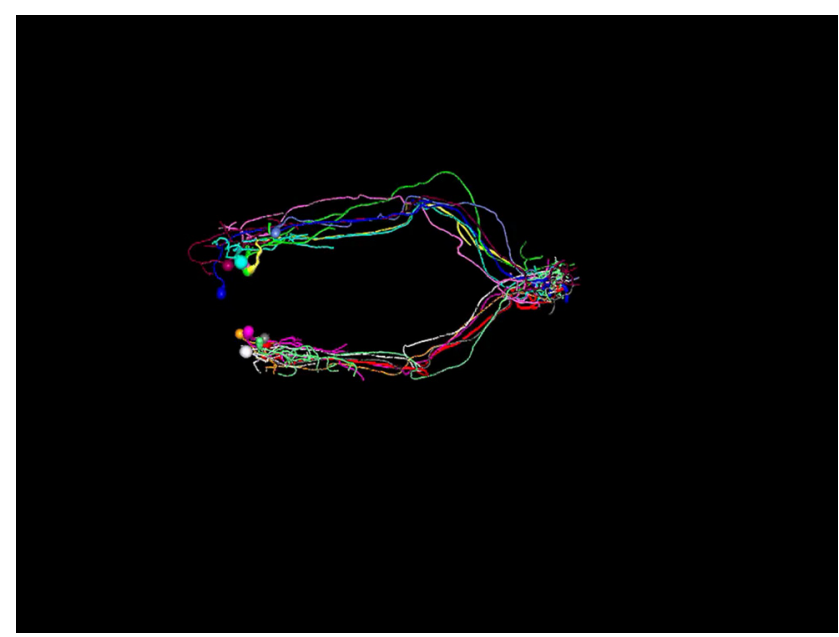

Movie 1. 3D rotation showing projections of hypophysiotropic Oxt-positive cells. Morphological reconstructions were manually registered from different $6 \mathrm{dpf}$ animals into one common model. Each cell is shown with a different color. See also Fig. 9A-A".

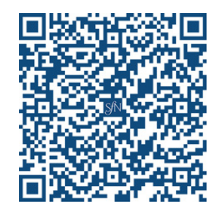

to the assumption that in specific situations (e.g., empathy, fear, pain, stress), dedicated subpopulations of neurons would modulate relevant brain regions to guide behavior toward survival of the individual and the species

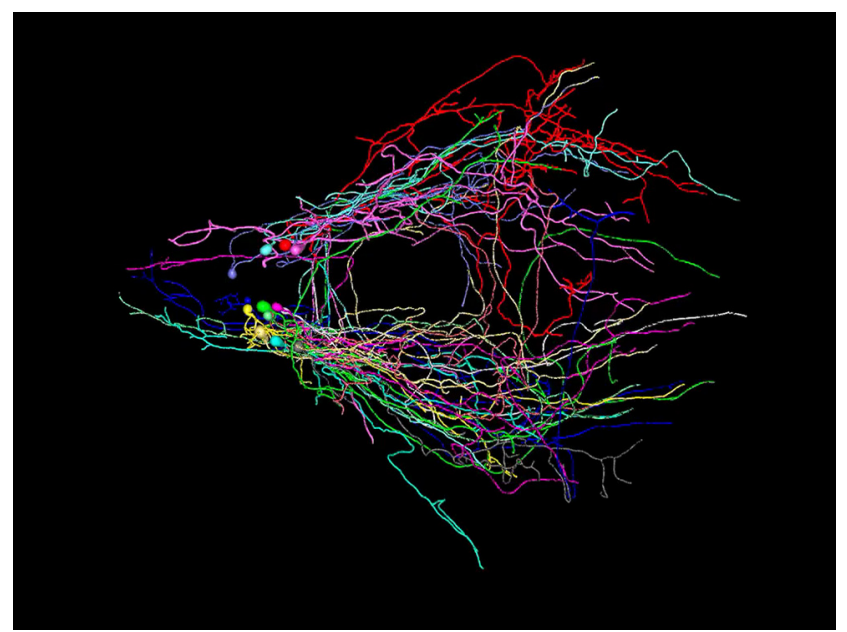

Movie 2. 3D rotation showing projections of encephalotropic Oxt-positive cells. Morphological reconstructions were manually registered from different 6-dpf animals into one common model. Each cell is shown with a different color. See also Fig. 9B- $B^{\prime \prime}$.

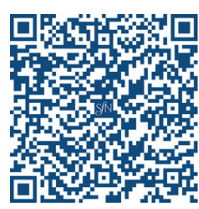

eNeuro.org 

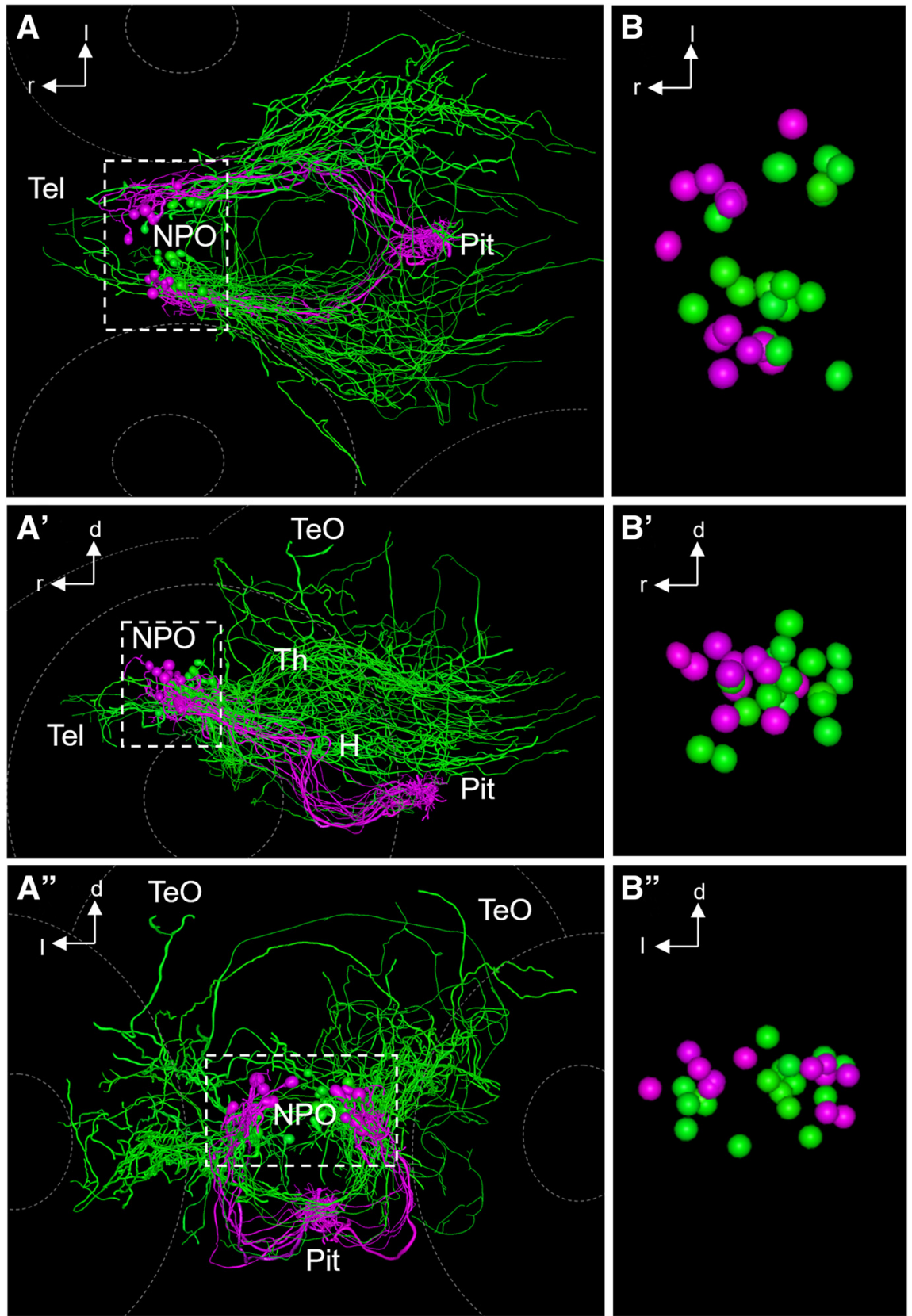

Figure 10. Comparison of hypophysiotropic and encephalotropic cell types after registration. $\boldsymbol{A}-\boldsymbol{A}^{\prime \prime}$, Comparison of encephalotropic (green) and hypophysiotropic (magenta) innervation of Oxt-producing cells, dorsal $(\boldsymbol{A})$, lateral $\left(\boldsymbol{A}^{\prime}\right)$, and frontal $\left(\boldsymbol{A}^{\prime \prime}\right)$ views. A 3D rotation of this dataset is provided as Movie 3. B-B", Magnified view of reconstructed soma centers after registration, dorsal (B), lateral $\left(\boldsymbol{B}^{\prime}\right)$, and frontal $\left(\boldsymbol{B}^{\prime \prime}\right)$ views. Three additional somata of encephalotropic oxytocinergic cells were added, since the soma was reconstructable. Note that the two morphological subtypes appear to possess segregated somata, suggesting a functionally relevant regionalization within the cluster of Oxt-producing cells. Hypophysiotropic cells reside in a more rostral part of the NPO compared with encephalotropic cells.

(Knobloch and Grinevich, 2014). However, the direct demonstration of distinct Oxt cell types based on their projections has been lacking, since the morphological diversity of oxytocinergic cells underlying circuit function is very difficult to extract from the large and opaque brains of rodents. Here we provide anatomical and morphological evidence for the existence of two major types of Oxt cells with distinct projections in larval zebrafish.
To visualize individual neurons in their entirety, two methods are commonly used: sparse single-color labeling and multicolor labeling of a group of neurons using Brainbow. Sparse labeling has been used in zebrafish to define dopaminergic (Tay et al., 2011) and olfactory projectomes (Miyasaka et al., 2014), yet such an approach depends on transient expression. The Brainbow method is an elegant tool for morphological reconstruction of multiple cells in 


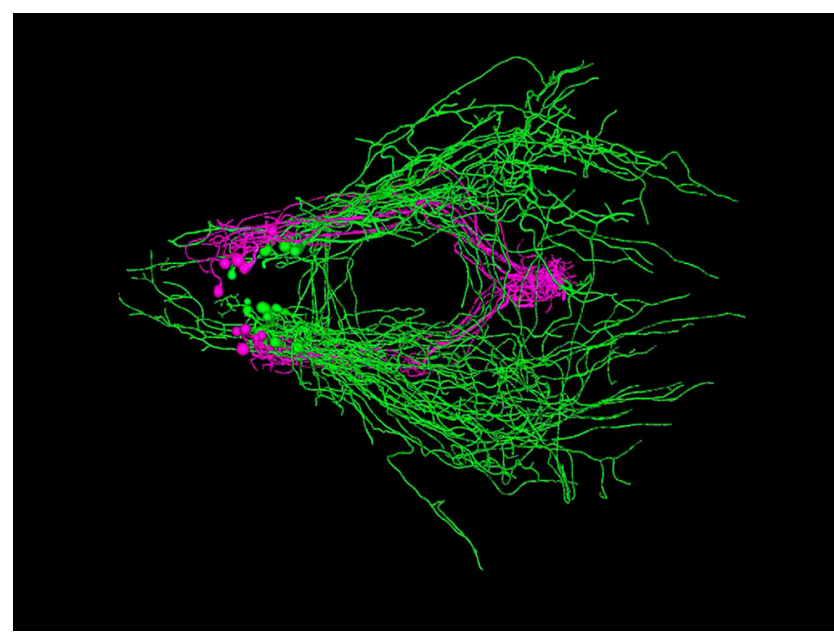

Movie 3. 3D rotation comparing hypophysiotropic and encephalotropic cell types. Morphological reconstructions were manually registered from different 6-dpf animals into one common model. The soma positions and projection patterns of hypophysiotropic cells (magenta) and encephalotropic cells (green) are separated. See also Fig. $10 A-A^{\prime \prime}$.

larval zebrafish (Robles et al., 2013), since it allows multicolor labeling in stable transgenic lines depending only on Cre recombinase, which can be provided via heat shock induction. In theory, this approach should allow more efficient single-cell reconstruction, but its actual efficiency in NPO cells was overall very low due to multiple selection steps that excluded many animals from further analysis (Fig. 4D). Because our results show that immunostaining is required for the confirmation of cell type identity and signal enhancement in deep regions, for future studies we suggest the use of separately detectable fluorophores for independent immunostaining, as reported previously (Cai et al., 2013). Although the registration approach we used might raise concerns about repeated sampling of the same cell type, we assume that the stochastic nature of random Brainbow recombination prevents such potential sampling bias. Oversampling of the same cell type is also unlikely because of considerable interindividual differences observed in cell numbers, soma positions, hemispheric distribution, innervation patterns, and coexpression levels across animals. The cells shown here are a small subset of a large dataset of imaged and reconstructed samples that included many unreconstructable or only partially reconstructable cells (because of overlap or crossing of branches with the same labeling). Nevertheless, in all these images and partial reconstructions, we saw the same two major types shown here.

Our results suggest that long-range projections of Oxt neurons are ancestral in the vertebrate brain, and that central Oxt projections are present during early development in zebrafish, unlike in developing mammals (Grinevich et al., $2015,2016)$. Our data are partially consistent with an earlier study in the rainbow trout, in which oxytocinergic cells also project widely throughout the brain, innervating ventral telencephalic, diencephalic, and mesencephalic regions in addition to the pituitary (Saito et al., 2004). Each of the analyzed cells projected to both the pituitary and central brain regions, suggesting that peripheral endocrine and central neuromodulatory functions are mediated by the same cell in the trout. Our results indicate that widespread oxytocinergic innervation throughout the brain is a feature of other teleosts as well.

In the plainfin midshipman, oxytocin innervates the ventral Tel, and such fibers terminate in the olfactory bulb (Goodson et al., 2003). This olfactory innervation was not found in larval zebrafish here, but could appear in juvenile or adult animals. Similar to the trout, projections into the Tel also were largely restricted to its ventral part. It should be noted that putative amygdala-homologous regions are located more dorsally in the Tel (Wullimann and Mueller, 2004; Maximino et al., 2013) and therefore are probably not innervated by Oxt cells in larval zebrafish at this stage, but such innervation could develop later. The hypothalamic and tectal innervation described in the trout was also observed here in larval zebrafish. However, the projection pattern groups we observed in larval zebrafish are different from those in the trout, where oxytocinergic neurons innervate the pituitary and other brain regions simultaneously (Saito et al., 2004). The zebrafish oxytocin system could thus be more differentiated than its trout homolog. A separation similar to our results, however, was suggested for the plainfin midshipman (Goodson et al., 2003).

A second magnocellular cell type innervating the neurohypophysis in mammals produces the closely related neuropeptide Avp. We performed morphological analysis of vasopressinergic cells using the same approach. Our data suggest that vasopressinergic projections are less abundant in extrahypothalamic regions than oxytocinergic projections (Herget, Salazar Thula, and Ryu, unpublished data), as was also reported for descending projections in rats (Buijs, 1978; Sawchenko and Swanson, 1982) and in various fishes (Van den Dungen et al., 1982; Goodson et al., 2003; Saito et al., 2004). This suggests that Oxt might regulate more diverse brain functions than Avp in larval zebrafish. This difference in complexity is thought to be greater in evolutionarily more advanced vertebrates, in which magnocellular Avp neurons remained structurally simpler, whereas Oxt neurons acquired a more complex shape (Grinevich et al., 2016). However, there are numerous extrahypothalamic structures expressing Avp in rodents (BNST, medial amygdala, etc.), which can contribute to modulation of various behaviors (Rood and De Vries, 2011). In contrast, Avp somata in larval zebrafish are restricted to the NPO (Herget et al., 2014).

We previously found that a minor population of oxytocinergic cells coexpresses crh (rarely), proenkephalin a (rarely), or proenkephalin $b$ (moderately) in $5 \mathrm{dpf}$ larvae (Herget and Ryu, 2015). Consistent with our current results, cells displaying this peptide coexpression are localized to the rostral half of the Oxt cluster, which according to our reconstruction and registration approach features predominantly neuroendocrine cells projecting to the pituitary. These results suggest that the Oxt population 
consists of a rostral neuroendocrine group that partially coreleases enkephalins (and rarely Crh) into the pituitary and a caudal neuromodulatory group that innervates distinct brain regions to regulate behavior. This apparent spatial separation is not without precedent. Oxytocinergic axons of some cells in the caudal PVN in rats display collateral branches, in contrast to the predominantly hypophysiotropic cells of the rostral and lateral PVN (Sofroniew, 1983). Oxt neurons projecting to regions other than the pituitary also cluster in the dorsoposterior part of the PVN in prairie voles, and such neurons were suggested to innervate the brainstem, whereas neuroendocrine cells tend to localize in the anterior PVN (Ross et al., 2009). Therefore, the clustering of Oxt neurons in zebrafish may have a similar trend as reported in rats and voles, although the mammalian Oxt system is far more complex and includes numerous accessory nuclei that may have extrahypothalamic projections as well (Steinman et al., 2016). Oxytocinergic innervation of the Ce was previously demonstrated in the trout (Saito et al., 2004). In 6-dpf larval zebrafish, Oxt immunostaining showed considerable interindividual variability in the degree of innervation of various regions, and the $\mathrm{Ce}$ was not innervated in all animals (Fig. 3), but such innervation could still develop later in those animals.

The Oxt system has received considerable attention for many years due to its key role in social behavior. Oxt is thought to increase the salience of sensory information linked to social cues (Grinevich et al., 2016). This involvement of the Oxt system in socially relevant brain regions has been suggested for different sensory modalities in different animal groups (vocal regions in songbirds, olfactory regions in rodents, and visual regions in primates), further supporting the concept of a modulatory function of locally released oxytocin in regions important for the social behavior of that species (Grinevich et al., 2016). In sonic fish, which use vocal-acoustic systems for mating communication, the brain regions involved are innervated by oxytocinergic cells (Goodson et al., 2003). Also, in adult zebrafish, Oxt and Avp injections modulate social and anxiety-related behavior (Braida et al., 2012). However, potential roles of Oxt in larval zebrafish in the context of social behavior have not been explored so far. It is tempting to speculate that the oxytocinergic system is involved in the modulation of visually guided social behavior in zebrafish, given its projections into the TeO. Such fibers tend to be situated within the deep neuropil, adjacent to the stratum periventriculare. Therefore, the innervated layers are probably the stratum album centrale or stratum griseum centrale (Nevin et al., 2008; Scott and Baier, 2009; Baier, 2013). In the trout, oxytocinergic fibers are found in deep tectal regions along the stratum periventriculare as well (Saito et al., 2004). Oxytocinergic fibers are also found within the stratum album centrale and stratum griseum centrale in the midshipman (Goodson et al., 2003). Tectal processing studies suggest that the deeper neuropil layers primarily have an output function, receiving input from the superficial layers (Nevin et al., 2010). Deep tectal layers are thought to not only process visual input, but also receive extraretinal afferents from other brain regions and from different sensory systems (Kinoshita and Ito, 2006). Local modulation of visual processing in deep layers of the tectal neuropil by afferents from nonvisual brain regions was also suggested for zebrafish (Robles et al., 2011). Our results suggest that oxytocinergic cells of the NPO constitute one of these regions. The tectal innervation found here in larval zebrafish is in agreement with the notion that these animals rely primarily on visual cues for social behavior.

Further studies of the Oxt system in different stages and under different environmental conditions, such as social enrichment or social deprivation, could illuminate the potential for plasticity of Oxt circuits for social behavior. Further investigation and manipulation of oxytocinergic cells in zebrafish will greatly enrich our understanding of one of the most remarkable and relevant vertebrate peptide systems, potentially in a faster and more comprehensive way than is currently possible in rodents.

\section{References}

Baier H (2013) Synaptic laminae in the visual system: molecular mechanisms forming layers of perception. Annu Rev Cell Dev Biol 29:385-416. CrossRef Medline

Braida D, Donzelli A, Martucci R, Capurro V, Busnelli M, Chini B, Sala M (2012) Neurohypophyseal hormones manipulation modulate social and anxiety-related behavior in zebrafish. Psychopharmacology (Berl) 220:319-330. CrossRef Medline

Brownstein MJ, Russell JT, Gainer H (1980) Synthesis, transport, and release of posterior pituitary hormones. Science 207:373-378. Medline

Buijs RM (1978) Intra- and extrahypothalamic vasopressin and oxytocin pathways in the rat. Pathways to the limbic system, medulla oblongata and spinal cord. Cell Tissue Res 192:423-435. Medline

Cai D, Cohen KB, Luo T, Lichtman JW, Sanes JR (2013) Improved tools for the Brainbow toolbox. Nat. Methods 10:540-547. CrossRef

Coffey CM, Solleveld PA, Fang J, Roberts AK, Hong SK, Dawid IB, Laverriere CE, Glasgow E (2013) Novel oxytocin gene expression in the hindbrain is induced by alcohol exposure: transgenic zebrafish enable visualization of sensitive neurons. PloS One 8:e53991. CrossRef Medline

Dölen G, Darvishzadeh A, Huang KW, Malenka RC (2013) Social reward requires coordinated activity of nucleus accumbens oxytocin and serotonin. Nature 501:179-184. CrossRef Medline

Eliava M, et al . (2016) A new population of parvocellular oxytocin neurons controlling magnocellular neuron activity and inflammatory pain processing. Neuron 89:1291-1304. CrossRef Medline

Evers JF, Schmitt S, Sibila M, Duch C (2005) Progress in functional neuroanatomy: precise automatic geometric reconstruction of neuronal morphology from confocal image stacks. J Neurophysiol 93:2331-2342. CrossRef

Goodson JL, Evans AK, Bass AH (2003) Putative isotocin distributions in sonic fish: relation to vasotocin and vocal-acoustic circuitry. J Comp Neur 462:1-14. CrossRef Medline

Grinevich V, Desarménien MG, Chini B, Tauber M, Muscatelli F, (2015) The central oxytocin pathways in mammalian ontogenesis: the late maturation and psychosocial diseases. Front Neuroanat 8:164. CrossRef Medline

Grinevich V, Knobloch-Bollmann HS, Eliava M, Busnelli M, Chini B (2016) Assembling the puzzle: pathways of oxytocin signaling in the brain. Biol Psychiatry 79:155-164. CrossRef Medline

Gutierrez-Triana JA, Herget U, Lichtner P, Castillo-Ramirez LA, Ryu $S$ (2014) A vertebrate-conserved cis-regulatory module for targeted expression in the main hypothalamic regulatory region for the stress response. BMC Dev Biol 14:41. CrossRef Medline 
Herget U, Wolf A, Wullimann MF, Ryu S (2014) Molecular neuroanatomy and chemoarchitecture of the neurosecretory preoptichypothalamic area in zebrafish larvae. J Comp Neur 522:15421564. CrossRef Medline

Herget U, Ryu S (2015) Coexpression analysis of nine neuropeptides in the neurosecretory preoptic area of larval zebrafish. Front Neuroanat 9:2. CrossRef Medline

Hosoya Y, Matsushita M (1979) Identification and distribution of the spinal and hypophyseal projection neurons in the paraventricular nucleus of the rat. A light and electron microscopic study with the horseradish peroxidase method. Exp Brain Res 35:315-331.

Kastenhuber E, Kratochwil CF, Ryu S, Schweitzer J, Driever W (2010) Genetic dissection of dopaminergic and noradrenergic contributions to catecholaminergic tracts in early larval zebrafish. J Comp Neur 518:439-458. CrossRef Medline

Kendrick KM, Keverne EB, Baldwin BA (1987) Intracerebroventricular oxytocin stimulates maternal behaviour in the sheep. Neuroendocrinology 46:56-61. Medline

Kinoshita M, Ito E (2006) Roles of periventricular neurons in retinotectal transmission in the optic tectum. Prog Neurobiol 79:112121. CrossRef Medline

Knobloch HS, Charlet A, Hoffmann LC, Eliava M, Khrulev S, Cetin AH, Osten P, Schwarz MK, Seeburg PH, Stoop R, Grinevich V (2012) Evoked axonal oxytocin release in the central amygdala attenuates fear response. Neuron 73:553-566. CrossRef Medline

Knobloch HS, Grinevich V (2014) Evolution of oxytocin pathways in the brain of vertebrates. Front Behav Neurosci 8:31. CrossRef Medline

Lee HJ, Macbeth AH, Pagani JH, Young WS 3rd (2009) Oxytocin: the great facilitator of life. Progr Neurobiol 88:127-151. CrossRef Medline

Lichtman JW, Livet J, Sanes JR (2008) A Technicolor approach to the connectome. Nat. Rev Neurosci 9:417-422. CrossRef Medline

Livet J, Weissman TA, Kang H, Draft RW, Lu J, Bennis RA, Sanes JR, Lichtman JW (2007) Transgenic strategies for combinatorial expression of fluorescent proteins in the nervous system. Nature 450:56-62. CrossRef Medline

Löhr H, Hammerschmidt M (2011) Zebrafish in endocrine systems: recent advances and implications for human disease. Annu Rev Physiol 73:183-211. CrossRef Medline

Ludwig M, Leng G (2006) Dendritic peptide release and peptidedependent behaviours. Nat Rev Neurosci 7:126-136. doi:10.1038/ nrn1845. CrossRef Medline

Maximino C, Lima MG, Oliveira KR, Batista Ede J, Herculano AM (2013) "Limbic associative" and "autonomic" amygdala in teleosts: a review of the evidence. J Chem Neuroanat 48-49:1-13. CrossRef Medline

Meyer-Lindenberg A, Domes G, Kirsch P, Heinrichs M (2011) Oxytocin and vasopressin in the human brain: social neuropeptides for translational medicine. Nat Rev Neurosci 12:524-538. CrossRef Medline

Miyasaka N, Arganda-Carreras I, Wakisaka N, Masuda M, Sümbül U, Seung HS, Yoshihara Y (2014) Olfactory projectome in the zebrafish forebrain revealed by genetic single-neuron labelling. Nat Commun 5:3639. CrossRef Medline

Nevin LM, Taylor MR, Baier H (2008) Hardwiring of fine synaptic layers in the zebrafish visual pathway. Neural Dev 3:36. CrossRef Medline

Nevin LM, Robles E, Baier H, Scott EK (2010) Focusing on optic tectum circuitry through the lens of genetics. BMC Biol 8:126. CrossRef Medline

Onaka T, Takayanagi Y, Yoshida M (2012) Roles of oxytocin neurones in the control of stress, energy metabolism, and social behaviour. J Neuroendocrinol 24:587-598. CrossRef Medline
Pedersen CA, Prange AJ Jr. (1979) Induction of maternal behavior in virgin rats after intracerebroventricular administration of oxytocin. Proc Natl Acad Sci U S A 76:6661-6665. Medline

Robles E, Smith SJ, Baier H (2011) Characterization of genetically targeted neuron types in the zebrafish optic tectum. Front Neural Circuits 5:1. CrossRef Medline

Robles E, Filosa A, Baier H (2013) Precise lamination of retinal axons generates multiple parallel input pathways in the tectum. J Neurosci 33:5027-5039. CrossRef Medline

Rood DR, De Vries GJ (2011) Vasopressin innervation of the mouse (Mus musculus) brain and spinal cord. J Comp Neur 519:24342474. CrossRef Medline

Ross HE, Cole CD, Smith Y, Neumann ID, Landgraf R, Murphy AZ, Young LJ (2009) Characterization of the oxytocin system regulating affiliative behavior in female prairie voles. Neuroscience 162: 892-903. CrossRef Medline

Saito D, Komatsuda M, Urano A (2004) Functional organization of preoptic vasotocin and isotocin neurons in the brain of rainbow trout: central and neurohypophysial projections of single neurons. Neuroscience 124:973-984. CrossRef Medline

Sawchenko PE, Swanson LW (1982) Immunohistochemical identification of neurons in the paraventricular nucleus of the hypothalamus that project to the medulla or to the spinal cord in the rat. $J$ Comp Neur 205:260-272. CrossRef Medline

Schmitt S, Evers JF, Duch C, Scholz M, Obermayer K (2004) New methods for the computer-assisted 3-D reconstruction of neurons from confocal image stacks. Neuroimage 23:1283-1298. CrossRef Medline

Scott EK, Baier H (2009) The cellular architecture of the larval zebrafish tectum, as revealed by Gal4 enhancer trap lines. Front Neural Circuits 3:13. CrossRef Medline

Sofroniew MV (1980) Projections from vasopressin, oxytocin, and neurophysin neurons to neural targets in the rat and human. $J$ Histochem Cytochem 25:475-478. CrossRef

Sofroniew MV (1983) Morphology of vasopressin and oxytocin neurones and their central and vascular projections. Prog Brain Res 60:101-114. CrossRef Medline

Steinman MQ, Duque-Wilckens N, Greenberg GD, Hao R, Campi KL, Laredo SA, Laman-Maharg A, Manning CE, Doig IE, Lopez EM, Walch K, Bales KL, Trainor BC (2016) Sex-specific effects of stress on oxytocin neurons correspond with responses to intranasal oxytocin. Biol Psychiatry 80:406-414. CrossRef Medline

Swanson LW, Hartman BK (1980) Biochemical specificity in central pathways related to peripheral and intracerebral homeostatic functions. Neurosci Lett 16:55-60. Medline

Swanson LW, Kuypers HGJM (1980) The paraventricular nucleus of the hypothalamus: cytoarchitectonic subdivisions and organization of projections to the pituitary, dorsal vagal complex, and spinal cord as demonstrated by retrograde fluorescence doublelabeling methods. J Comp Neur 194:555-570. CrossRef

Tay TL, Ronneberger O, Ryu S, Nitschke R, Driever W (2011) Comprehensive catecholaminergic projectome analysis reveals singleneuron integration of zebrafish ascending and descending dopaminergic systems. Nat Commun 2:171. CrossRef Medline

Van den Dungen HM, Buijs RM, Pool CW, Terlou M (1982) The distribution of vasotocin and isotocin in the brain of the rainbow trout. J Comp Neur 212:146-157. CrossRef Medline

Westerfield M (2000) The Zebrafish Book. A Guide for the Laboratory Use of Zebrafish (Danio rerio). Fourth Edition. Eugene: Univ. of Oregon Press.

Wullimann MF, Mueller T (2004) Teleostean and mammalian forebrains contrasted: evidence from genes to behavior. J Comp Neur 475:143-162. CrossRef Medline 